\title{
Stress-strain Behavior of Steel-Polypropylene Hybrid Fiber Reinforced Concrete Under True Triaxial Compression
}

\author{
SU jie ${ }^{2, a}, \mathrm{CHI}$ Yin $^{1, b^{*}}$ \\ ${ }^{1}$ School of Civil Engineering, Wuhan University, Wuhan 430072, China \\ ${ }^{2}$ Wuhan University of Engineering Science, Wuhan 430200, China \\ a11497993@qq.com, byin.chi@whu.edu.cn
}

\begin{abstract}
Keywords: Hybrid fiber reinforced concrete; True triaxial compression; Stress-strain relation; Volumetric deformation.

Abstract. This paper investigates the stress-strain behavior of steel-polypropylene hybrid fiber reinforced concrete (HyFRC) under true triaxial compression. Three definitive lateral pressure combinations of $5 / 10 \mathrm{MPa}, 4 / 15 \mathrm{MPa}$ and $3 / 20 \mathrm{MPa}$ were performed for different fiber volume fractions and aspect ratios. Axial stress-strain relations and volumetric-axial strain relations were analyzed with respect to the variation of fiber reinforcement index. The test results showed that the steel fiber was observed to be a major contributor to the strength of HyFRC under true triaxial compression in that strength was dramatically improved with increases in both volume fraction and aspect ratio. The polypropylene fiber was found to have no significant impact on strength under all loading conditions, while the ductile performance was significantly improved by increasing the volume fraction of the polypropylene fiber. In addition, both the steel fiber and polypropylene fiber were observed positively improved the volumetric-axial strain curve, the steel fiber mainly contributed to the delaying of the onset of dilation while polypropylene fibers acted primarily to reduce the dilation rate. It is concluded that the behavior of HFRC is effectively the combined behavior of both steel fiber reinforced concrete and polypropylene fiber reinforced concrete, benefiting from the advantages of both steel fiber and polypropylene fiber and exhibiting a synergistic response in respect of strength, deformation capacity and post peak ductility.
\end{abstract}

\section{Introduction}

Fiber reinforced concrete (FRC), which is now recognized by engineers as a viable concrete reinforcement solution, has seen widespread application in the construction industry in recent decades [1-3]. Nowadays, fiber reinforcing technology has led to the hybrid fiber reinforced concrete (HyFRC) due to its favorable mechanical behavior [4-9].

To date, considerable research efforts have been made to study the strength and stress-strain relations of FRC [10-13]. The failure modes of FRC, in particular for single steel fiber reinforced concrete under multiaxial stress were also analyzed [14-17]. However, early concerns were mainly concentrated on the single fiber reinforced concrete under uniaxial or biaxial loadings $[6,12,18]$, whilst the effect of hybrid fibers on the whole stress-strain relations under true triaxial compression has not been well documented from the author's knowledge. As the HyFRC structures are typically subjected to complex loadings in reality, it is essential to address and analyze the stress-strain behavior of HyFRC under multiaxial stress states that determines not only the ultimate bearing capacity of an entire structure but also the local failure and the stability problem.

The objective of this paper is to investigate the stress-strain behavior of steel-polypropylene HyFRC under true triaxial compressions. Three definitive lateral pressure combinations of $5 / 10 \mathrm{MPa}, 4 / 15 \mathrm{MPa}$ and $3 / 20 \mathrm{MPa}$ are considered in this study. The axial stress-strain curves and volumetric-axial strain curves of HyFRC for different fiber reinforcement index are presented. 


\section{Experimental program}

\section{Materials and Mix proportions}

The plain concrete mixtures were designed and specified at a 28-day compressive strength of 60Mpa. Ordinary Portland cement (P.O 42.5) was used as the binder for the mixtures. Crushed granitic rocks of sizes between 5 20mm were used as the coarse aggregates. Normal river sand including $5 \%$ of water (by weight) with fineness modulus of 2.7 was used as fine aggregates. Efficiency highly efficient water reducing agent with a reducing rate of about $20 \%$ was used in the mix design. The mix design by weight of the plain concrete mixture was in the ratio of 1:0.34:1.80:2.49 (cement:water:sand:coarse aggregate) and designed according to reference[19].

Corrugated steel fibers (Fig.1) were used in volume fractions of $0.5 \%, 1 \%$ and $1.5 \%$ and aspect ratios (length/diameter, L/D) of 30 and 60 were employed. The steel fiber (SF) has a minimum tensile strength of $600 \mathrm{MPa}$ with a density of $7800 \mathrm{~kg} / \mathrm{m}^{3}$. In addition, monofilament polypropylene fibers (PF) (Fig.1), with a diameter of $0.048 \mathrm{~mm}$, were used in volume fractions of $0.05 \%, 0.1 \%$ and $0.15 \%$. The lengths of the PF used in this study were selected to be $8 \mathrm{~mm}$ and $19 \mathrm{~mm}$, corresponding to aspect ratios of 167 and 396 respectively. The PF has an elongation rate larger than $15 \%$ with a tensile strength around 400MPa.
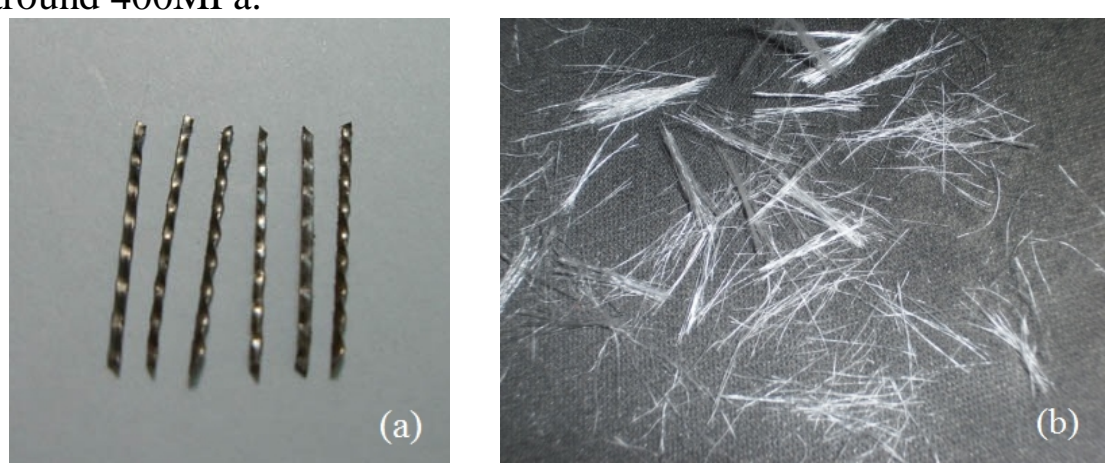

Fig.1 Fibers used in the true triaxial compression test (a) SF; (b) PF

In addition to the plain concrete which was used as a reference, a total of 75 specimens were tested including single steel fiber reinforced concrete (SFRC) and single polypropylene fiber reinforced concrete (PFRC). The fiber reinforcement indexes in terms of volume fraction and aspect ratio were the main variables considered and their respective values for each specimen is summarized in Table 1.

\section{Specimens Preparation}

The mix design of HyFRC was undertaken in accordance to the Technical specification for FRC structures [19]. Firstly, the coarse aggregates combined with SF were stirred for 1 to 2 minutes. The fine aggregates and cement were then vibrated in a mixer for 1 to 2 minutes. Within 1 to 2 minutes of vibrating, the PF was gradually added. Finally, the water and water reducing agent were added and mixed to complete the mixture preparation procedure. Specimens of size $150 \times 150 \times 150 \mathrm{~mm}$ were cast in cubic-shaped steel molds and compacted on a vibration table. All the specimens were demolded after 24 hours and stored in a curing room at a temperature of $20 \pm 2^{\circ} \mathrm{C}$ and a relative humidity of $95 \%$ until 28 days strength was achieved.

\section{True triaxial test Set-ups}

The true triaxial testing system used was specially manufactured by the Science Academic Research Institute of Yangtze River in China. The design of the apparatus is such that it was housed in a tunnel to ensure the vertical rigid of the device. Fig. 2 gives a schematic diagram and the lateral profile of the apparatus. It has a 1500tonne load capacity and is able to apply a lateral pressure of up to $20 \mathrm{MPa}$. It can accommodate a $150 \mathrm{~mm} \times 150 \mathrm{~mm} \times 150 \mathrm{~mm}$ cubic specimen(Fig.2a). A rolling system was also designed that facilitates the installation of specimens (Fig.2b).Three directions of lateral pressures were separately controlled by a servo-hydraulic system. 


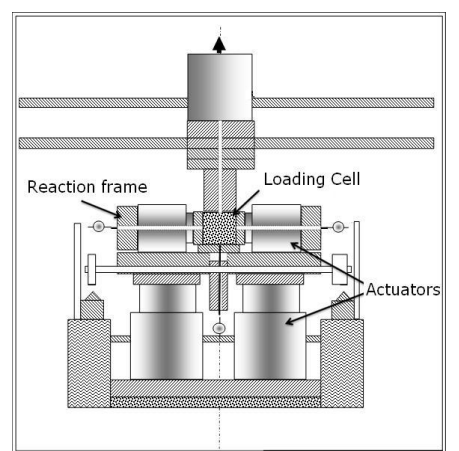

(a)Triaxial testing devices

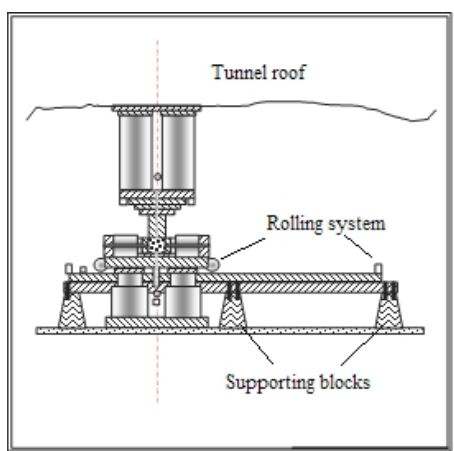

(b) Lateral profile

Fig. 2 Schematic diagram of true triaxial testing system

Axial loads were applied to the specimen via actuators fitted at the bottom of the device and lateral loads were applied by actuators fitted against the device's rigid reaction frame. All the pressures were measured by pressure transducers. Axial and lateral extensometers were used to measure the deformations caused by the imposed stresses. All the experimental data were collected by an automated collection system. Under true triaxial compression, a displacement control with a $0.005 \mathrm{~mm} / \mathrm{s}$ loading velocity was applied in the axial direction $\left(\sigma_{3}\right.$ direction) until ultimate failure occurred. The lateral pressures $\left(\sigma_{1}<\sigma_{2}\right)$ were designated as $5 / 10 \mathrm{MPa}, 4 / 15 \mathrm{MPa}$ and $3 / 20 \mathrm{MPa}$ respectively in accordance to the loading capacity of the testing machine.

Table 1 Fiber mix and content used in the true triaxial compression test

\begin{tabular}{cccccc}
\hline Batch & $\begin{array}{c}\text { Specimens } \\
\text { Identifier }\end{array}$ & L/D(SF) & L/D(PF) & $\begin{array}{c}\text { Volume ratio } \\
\text { of SF[\%] }\end{array}$ & $\begin{array}{c}\text { Volume ratio } \\
\text { of PF[\%] }\end{array}$ \\
\hline 1 & SA05PA05 & 30 & 167 & 0.5 & 0.05 \\
2 & SA05PB05 & 30 & 396 & 0.5 & 0.05 \\
3 & SB05PA05 & 60 & 167 & 0.5 & 0.05 \\
4 & SB05PB05 & 60 & 396 & 0.5 & 0.05 \\
5 & SA05PA10 & 30 & 167 & 0.5 & 0.10 \\
6 & SA05PA15 & 30 & 167 & 0.5 & 0.15 \\
7 & SA10PA05 & 30 & 167 & 1.0 & 0.05 \\
8 & SA10PA10 & 30 & 167 & 1.0 & 0.10 \\
9 & SA10PB10 & 30 & 167 & 1.0 & 0.10 \\
10 & SB10PA10 & 60 & 396 & 1.0 & 0.10 \\
11 & SB10PB10 & 60 & 167 & 1.0 & 0.10 \\
12 & SA10PA15 & 30 & 396 & 1.0 & 0.15 \\
13 & SA15PA05 & 30 & 167 & 1.5 & 0.05 \\
14 & SA15PA10 & 30 & 167 & 1.5 & 0.10 \\
15 & SA15PA15 & 30 & 167 & 1.5 & 0.15 \\
16 & SA15PB15 & 30 & 396 & 1.5 & 0.15 \\
17 & SB15PA15 & 60 & 167 & 1.5 & 0.15 \\
18 & SB15PB15 & 60 & 396 & 1.5 & 0.15 \\
19 & SA05 & 30 & -- & 0.5 & - \\
20 & SA10 & 30 & -- & 1.0 & -- \\
21 & SA15 & 30 & -- & 1.5 & -- \\
22 & PA05 & -- & 167 & -- & 0.05 \\
23 & PA10 & -- & 167 & -- & 0.10 \\
24 & PA15 & -- & 167 & -- & - \\
25 & C60 & -- & -- & -- & \\
\hline
\end{tabular}




\section{Test results and discussions}

\section{Axial stress-strain curves.}

The following sections show the influence of the hybrid fibers on axial stress-strain behavior and volumetric strain-axial strain behavior.

Influence of SF volume fraction.Fig. 3 compares the typical stress-strain curves of SFRC and plain concrete loaded axially for samples under three different lateral pressure combinations. It is observed that the ultimate strength improves with an increasing SF volume fraction. It is also clearly shown that the deformation reduces with the increase in the volume fraction for the same lateral pressure combination, which is thought to delay the onset of strength loss owing to a crack arrest mechanism.
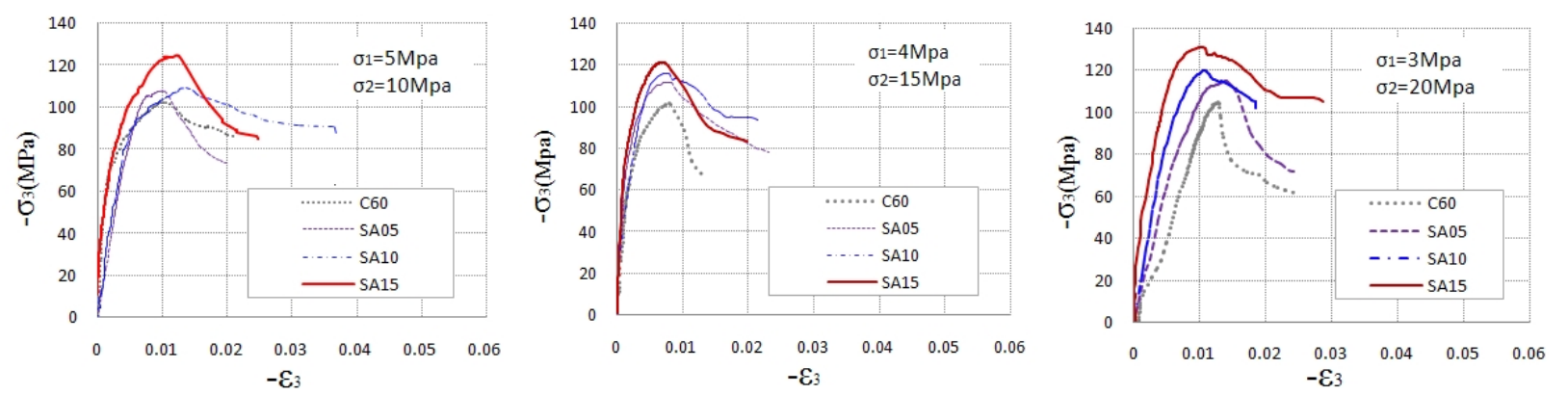

Fig.3 Axial stress-strain curves of SFRC under different loadings

Fig.4 illustrates the axial stress-strain curves of HyFRC under a lateral pressure combination of $3 / 20 \mathrm{MPa}$ for a changing $(0.5 \%$ to $1.5 \%) \mathrm{SF}$ volume fraction, the $\mathrm{PF}$ volume fractions were respectively fixed at $0.05 \%, 0.10 \%$ and $0.15 \%$. The aspect ratios of both the SF and PF were kept constant in each instance.
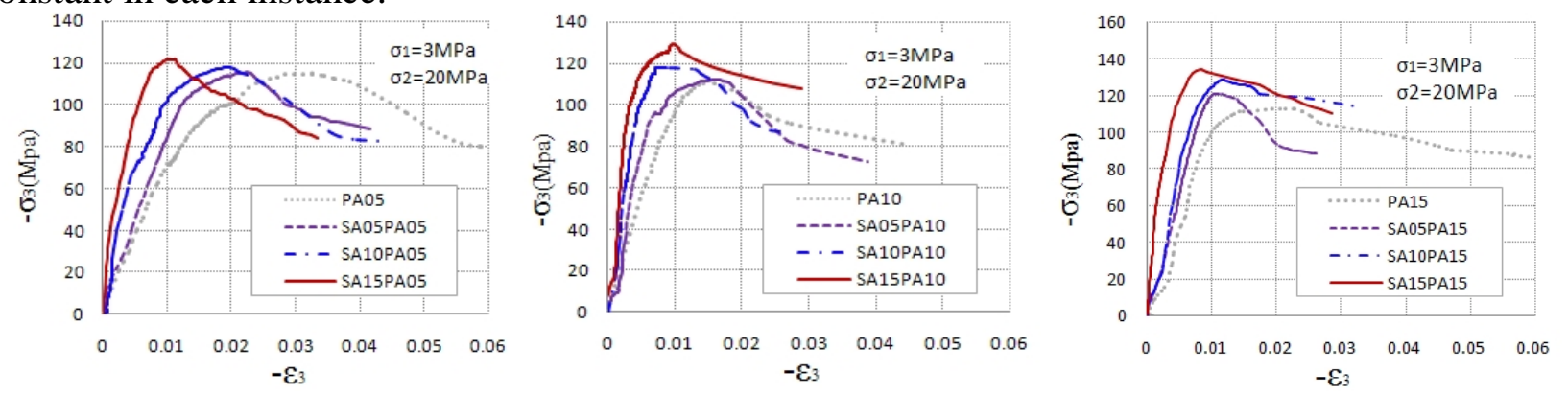

Fig.4 Comparison of axial stress-strain curves of HyFRC under 3/20MPa loadings

In all the cases shown, the strengths of HyFRC are improved upon the addition of SF. It is also obvious that stiffness in the pre-peak region of the stress-strain curve of HyFRC profoundly improves with increasing SF volume fraction compared to PFRC. This improvement is because the SF has relatively higher modulus than concrete, which in line with the theory of composite materials causes an increase in the integral modulus and hence stiffness of the composite. Furthermore, HyFRC exhibits more ductility at post peak performance in comparison to plain concrete. However, there is no evidence of change in the post peak response corresponding to the increase in the volume fraction of the SF.

Influence of PF volume fraction.Fig.5 shows the axial stress-strain curves of PFRC and plain concrete under three different lateral pressure combinations. The aspect ratios of both SF and PF were kept constant throughout. It is shown that the triaxial strength initially improves to certain degree upon the addition of PF (up to 10\% increase). However, the plot shows no further improvement in strength for increasing PF volume fractions. In some cases (volume fraction of $0.15 \%$ ), strength is noted to actually decrease. However, with respect to the post-peak behavior, the advantage of adding of PF is clearly demonstrated. The ductile performance is significantly improved with increasing volume fraction of PF. 
Fig. 6 plots the typical axial stress-strain curves of changing $(0.05 \%$ to $0.15 \%)$ PF volume fractions under three different lateral pressure combinations, where the SF volume fractions are fixed at $0.5 \%$.
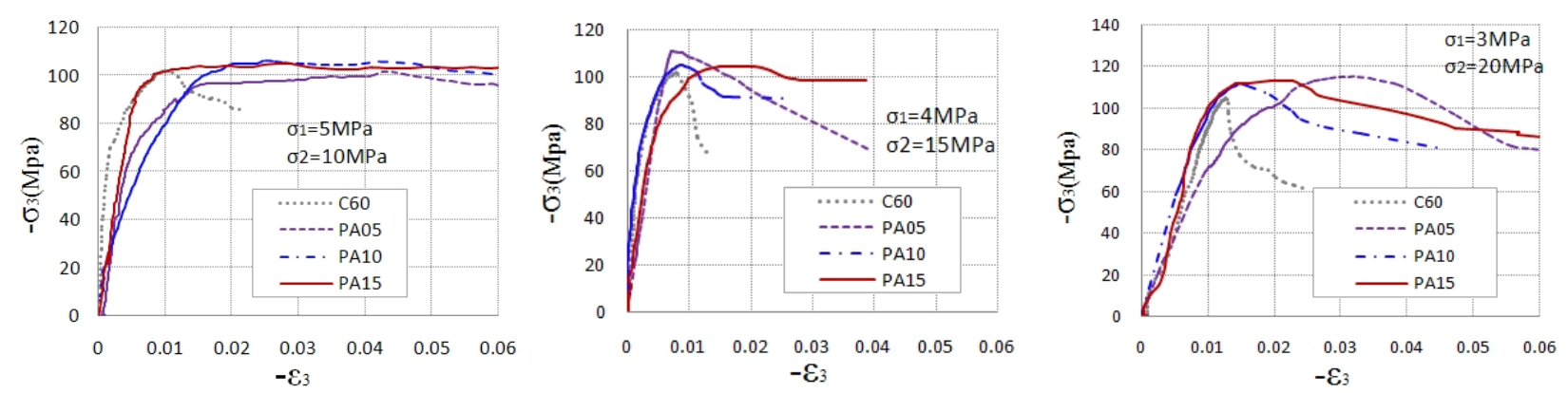

Fig.5 Axial stress-strain curves of PFRC under different loadings
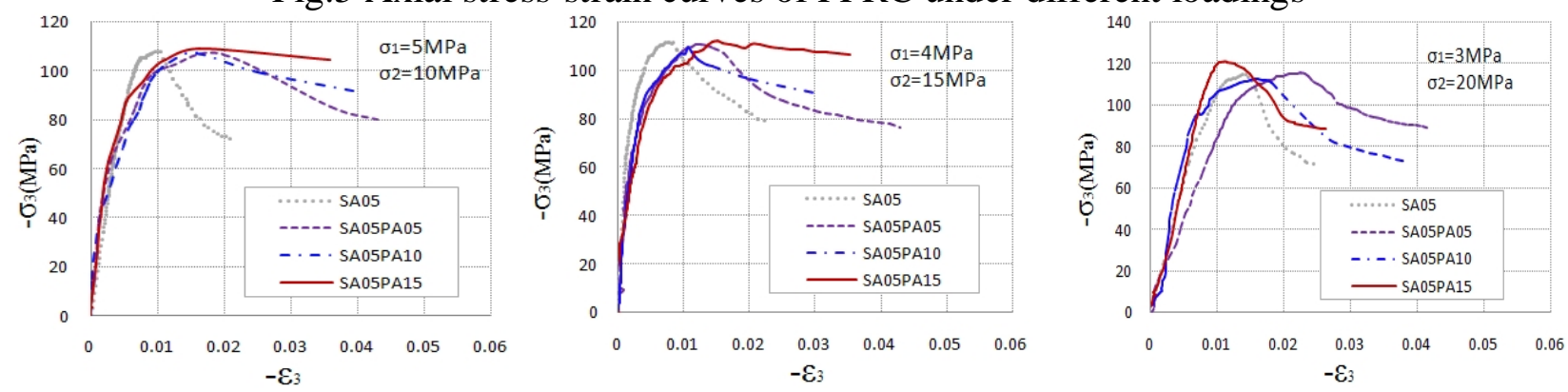

Fig.6 Axial stress-strain curves of HyFRC under different loadings

It can be seen that the strengths of the HyFRC samples fluctuate with an increase in PF volume fraction, some of the results show slight improvement in strength. In comparison to SFRC, the post-peak response of HyFRC showed substantial improvement with increasing PF volume fraction with the strength degradation effectively eliminated at the expense of slight strength fluctuations. It can therefore be concluded that the behavior of HyFRC is in fact a combined behavior of both SFRC and PFRC, benefitting from the advantages of both SF and PF have to offer in terms of strength, deformation capacity and post peak ductility. It was also found that the response of HyFRC is more balanced than that of single SFRC or PFRC.

Influence of SF aspect ratio.Fig.7 shows the typical influence of the SF aspect ratio on axial stress-axial strain curves under lateral pressure combination $5 / 10 \mathrm{MPa}$ for different equally combined SF and PF volume fractions. For all the cases, the aspect ratio of 60 exhibits a more superior ductile performance in its post peak response than of the aspect ratio of 30 . At the same time, peak strength is also noted to have improved for samples with a higher aspect ratio of SF.
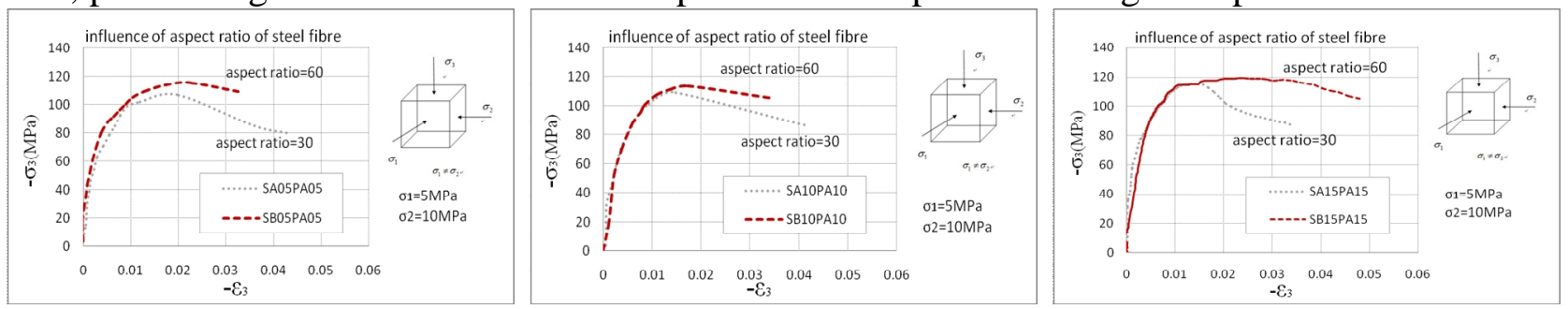

Fig.7 Influence of SF aspect ratio on stress-strain relation under 5/10MPa loading

Influence of PF aspect ratio.Fig.8 describes the typical influence of different PF aspect ratios under a lateral pressure combination of $5 / 10 \mathrm{MPa}$ on the stress-strain behavior of HyFRC. For every change in PF aspect ratio, the SF aspect ratio was kept constant. Furthermore, although varied thrice, equal volume fractions of steel and polypropylene fibers were utilized in each instance. The samples with PF of aspect ratio 396, beyond the peak stress are noted to generally have lower strength loss rate compared to samples with fiber aspect ratios of 167 . However, no significant 
strength improvement is observed to occur as a result of the change of polypropylene fiber aspect ratio.
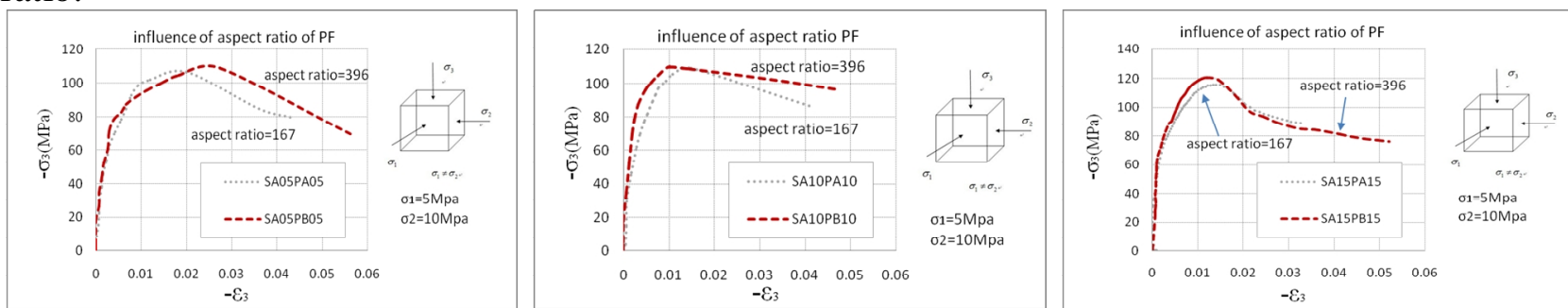

Fig.8 Influence of PF aspect ratio on stress-strain relation under 5/10MPa loading

\section{Volumetric strain-axial strain relations}

It has been noted from many experimental observations that the volumetric strain $\left(\varepsilon_{v}\right)$ of the plain concrete under compression undergoes a contraction and dilation as it is with the cracking process [20]. It has also been shown that the slope of a volumetric strain-axial strain curve in the dilation region is representative of concrete's post peak deformation capacity and ductility i.e., a sharper slope corresponds to quicker dilation or expansion, resulting in lower ductile performance.
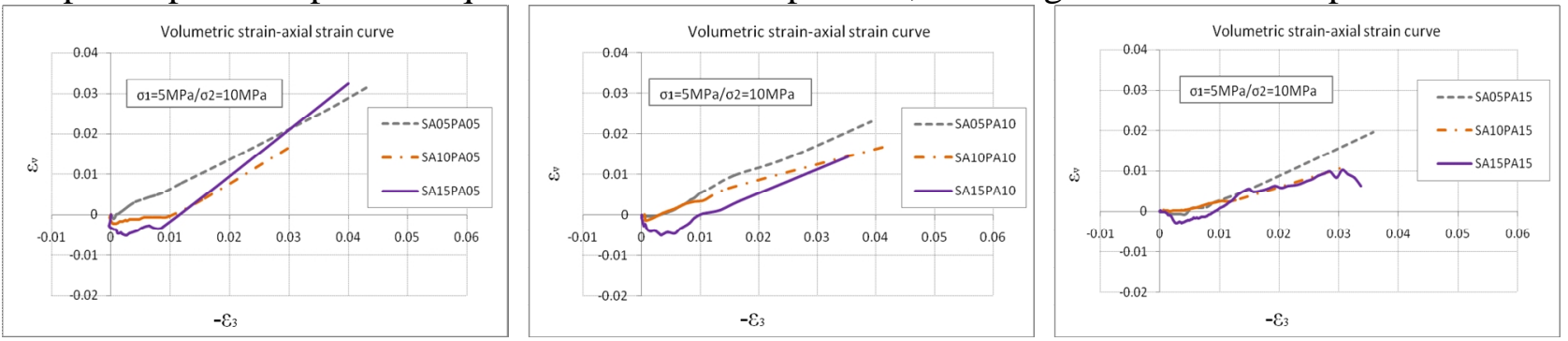

Fig.9 $\varepsilon_{v}$ versus $\varepsilon_{3}$ relations of HyFRC under 5/10MPa loading

Fig.9 shows the volumetric-axial strain plots of HyFRC with different SF volume fractions under lateral pressure combination of $5 / 10 \mathrm{MPa}$. Note that the volumetric strain was computed as $d V / V$, and applying the case of infinitesimal deformation, $\varepsilon_{v}$ was calculated using the trace of the three principle strains $\left(\varepsilon_{v}=\operatorname{tr}(\boldsymbol{\varepsilon})=\varepsilon_{1}+\varepsilon_{2}+\varepsilon_{3}\right)$.

From the plots, there is evidence of a more protracted contraction phase preceding the onset of dilation as the SF volume fraction is progressively increased. This can be seen where the volumetric-axial strain curve intersects the horizontal axis late, indicating a late dilation. The results imply that the deformation of the concrete specimen is essentially restricted and ultimate failure substantially moderated by the increasing SF volume fractions. It is thought that the aforementioned behavior could eventually improve post cracking response by increasing deformability and residual stiffness. This phenomenon was also observed by [20]. On the odd occasion, SF volume fractions appears to have had a slightly negative effect on the ductility performance of the concrete in that the dilation rate is occasionally increased with an increasing amount of SF(Fig.9a).
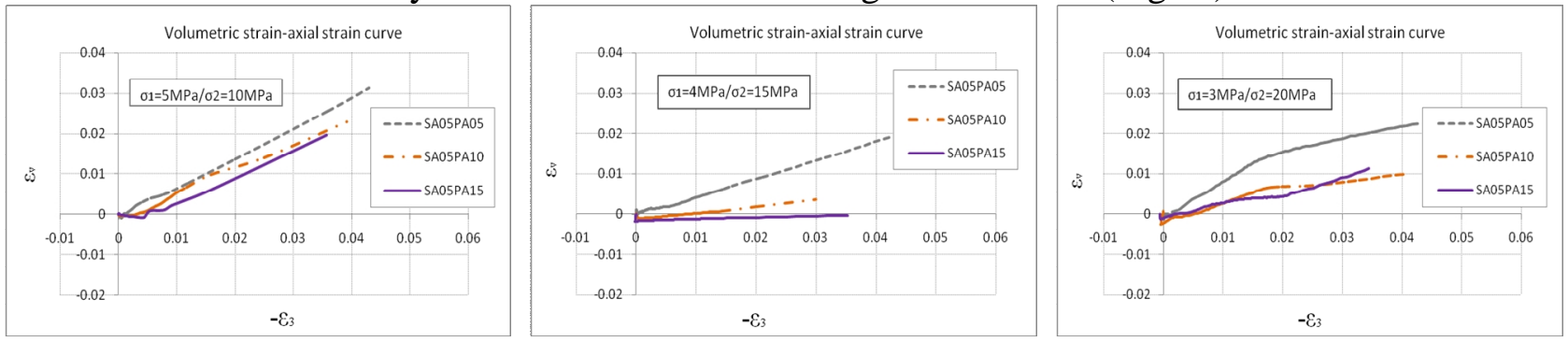

Fig.10 $\varepsilon_{v}$ versus $\varepsilon_{3}$ relations of HyFRC under different loadings

In Fig.10, the volumetric-axial strain curve of HyFRC with different volume fractions of PF under lateral pressure combination of $5 / 10 \mathrm{MPa}$ are shown. It can be seen that PF volume fraction 
has an insignificant effect on the degree of contraction in contractive range. Furthermore, the observed rate of dilation decreases as a result of increase in PF volume fraction. By comparing the figures above, it is interesting to observe that the expansion rate of HFRC reduces significantly as the volume fraction of polypropylene fiber is increased from $0.5 \%$ up to $0.1 \%$. However, at a PF of $0.15 \%$, there is no noticeable reduction in the expansion rate compared to the $0.1 \% \mathrm{PF}$ content. It is concluded that a relative high volume fraction of $\mathrm{PF}(0.15 \%)$ has an insignificant effect on HFRC ductility in comparison to a $0.1 \%$ volume fraction. A volume fraction of $0.1 \%$ can be regarded as the threshold amount of PF content. This conclusion is consistent with the findings of the other researchers $[21,22]$.

\section{Conclusions}

Triaxial strength was found to invariably improve by the inclusion of hybrid fibers. The SF was observed to be a major contributor to the triaxial strength that was dramatically improved with increases in both volume fraction and aspect ratio. The PF has no significant impact on strength under all loading conditions.

It was generally observed that increasing the volume fraction of SF had no effect on the post peak response, while the ductile performance was significantly improved by increasing the volume fraction of the PF. The rate of strength loss in the post peak region was invariably reduced at the expense of slight strength degradation.

Both the SF and PF were observed positively improved the volumetric-axial strain behavior. The specimen volumetric deformation was essentially restricted and ultimate failure substantially moderated and delayed for increasing amounts of hybrid fibers. The SF mainly contributed to the delaying of the onset of dilation while PF acted primarily to reduce the dilation rate.

The behavior of HFRC is effectively the combined behavior of both SFRC and PFRC, benefiting from the advantages of both SF and PF and exhibiting a synergistic response in respect of strength, deformation capacity and post peak ductility.

\section{Acknowledgement}

The present work was funded by the Natural Science Foundation of China(Grant No.51278388). The financial support is gratefully acknowledged.

\section{References}

[1] M. di Prisco, G. Plizzari, L. Vandewalle, Fibre reinforced concrete: new design perspectives, MATER STRUCT 42 (2009) 1261-1281.

[2] S.F.U. Ahmed, M. Maalej, P. Paramasivam, Flexural responses of hybrid steel-polyethylene fiber reinforced cement composites containing high volume fly ash, CONSTR BUILD MATER 21 (2007) 1088-1097.

[3] L. Huang, L. Xu, Y. Chi, H. Xu, Experimental investigation on the seismic performance of steel-polypropylene hybrid fiber reinforced concrete columns, CONSTR BUILD MATER 87 (2015) 16-27.

[4] W. Yao, J. Li, K. Wu, Mechanical properties of hybrid fiber-reinforced concrete at low fiber volume fraction, CEMENT CONCRETE RES 33 (2003) 27-30.

[5] C.X. Qian, P. Stroeven, Development of hybrid polypropylene-steel fibre-reinforced concrete, CEMENT CONCRETE RES 30 (2000) 63-69. 
[6] S.J. Pantazopoulou, M. Zanganeh, Triaxial Tests of Fiber-Reinforced Concrete, J MATER CIVIL ENG 13 (2001) 340-348.

[7] Y. Chi, L. Xu, G. Mei, N. Hu, J. Su, A unified failure envelope for hybrid fibre reinforced concrete subjected to true triaxial compression, COMPOS STRUCT 109 (2014) 31-40.

[8] Y. Chi, L. Xu, H. Yu, Constitutive modeling of steel-polypropylene hybrid fiber reinforced concrete using a non-associated plasticity and its numerical implementation, COMPOS STRUCT 111 (2014) 497-509.

[9] Y. Chi, L. Xu, H. Yu, Plasticity Model for Hybrid Fiber-Reinforced Concrete under True Triaxial Compression, J ENG MECH 140 (2014) 393-405.

[10]Z. Wang, Y. Liu, R.F. Shen, Stress-strain relationship of steel fiber-reinforced concrete under dynamic compression, CONSTR BUILD MATER 22 (2008) 811-819.

[11] T.C. Wang, H.L. Zhao, J.J. Hao, J.Q. Zu, Research on Compressive Stress - Strain Relationship of Fiber Reinforced Concrete, ADV MATER RES 168-170 (2010) 384-392.

[12]X.D Hu, R Day, D. P, Biaxial Failure Model for Fiber Reinforced Concrete, J MATER CIVIL ENG 15 (2003) 609-615.

[13] Y. Ding, W. Kusterle, Compressive stress-strain relationship of steel fibre-reinforced concrete at early age, CEMENT CONCRETE RES 30 (2000) 1573-1579.

[14] M. Hsie, C. Tu, P.S. Song, Mechanical properties of polypropylene hybrid fiber-reinforced concrete, MATER SCI ENG: A 494 (2008) 153-157.

[15]S. Swaddiwudhipong, P.E.C. Seow, Modelling of steel fiber-reinforced concrete under multi-axial loads, CEMENT CONCRETE RES 36 (2006) 1354-1361.

[16] J.C. Chern, H.J. Yang, H.W. Chen, Behavior of Steel Fiber Reinforced Concrete in Multiaxial Loading, ACI MATER J 89 (1992) 32-40.

[17]X. Lu, C.T. Hsu, Behavior of high strength concrete with and without steel fiber reinforcement in triaxial compression, CEMENT CONCRETE RES 36 (2006) 1679-1685.

[18]K. Ramesh, D.R. Seshu, M. Prabhakar, Constitutive behaviour of confined fibre reinforced concrete under axial compression, CEMENT CONCRETE COMPOS 25 (2003) 343-350.

[19]CECS 38:2004, Technical specification for fiber reinforced concrete structures, in: C.E.C.S. Association (ed.), China Planning Press, Beijing, 2004. (inChinese)

[20]I. Imran, S.J. Pantazopoulou, Experimental Study of Plain Concrete under Triaxial Stress, ACI MATER J 93 (1996) 589-600.

[21] Y. Chi, L. Xu, Y. Zhang, Experimental Study on Hybrid Fiber-Reinforced Concrete Subjected to Uniaxial Compression, J MATER CIVIL ENG 26 (2014) 211-218.

[22]Y. Zhang, Study on Uniaxial Compressive Constitutive Relationship and Uniaxial Tensile Behavior of Steel- Polypropylene Hybrid Fiber Reinforced Concrete, Wuhan University, Wuhan, 2010. (inChinese) 